\title{
Cognitive function in offspring of mothers with gestational diabetes-the role of insulin receptor
}

\begin{abstract}
There is increasing evidence that the offspring of women with gestational diabetes during pregnancy are at increased risk for the neurocognitive abnormalities. Moreover, the exact molecular mechanism by which gestational diabetes affects the developing central nervous system (CNS) remains to be defined. In the recent decades, it found that the Insulin has a crucial role in the development and function of the brain in both fetuses and adults. The researchers found that the alteration in expression/localization of insulin receptor (InsR) in the brain may be part of the cascade of events through which gestational diabetes affects the newborn's CNS structures. Dissecting out the mechanisms responsible for gestational diabetes-related changes in the development of CNS is helping to prevent from impaired neurocognitive functions in offspring.
\end{abstract}

Keywords: Gestational Diabetes, Cognition, Insulin, Offspring, Neurocognitive, Teratogenic

\author{
Volume 2 Issue 7 - 2016 \\ JavadHami, ${ }^{1,2}$ Mehran Hosseini, ${ }^{3}$ Ghasem \\ Ivar,' Saeed Vafaei-Nezhad,' Marzieh Keivan, ${ }^{4}$ \\ Hossein Haghir ${ }^{5,6}$ \\ 'Department of Anatomical Sciences, Birjand University of \\ Medical Sciences, Iran \\ ${ }^{2}$ Cellular and Molecular Research Center, Birjand University of \\ Medical Sciences, Iran \\ ${ }^{3}$ Department of Public Health, Birjand University of Medical \\ Sciences, Iran \\ ${ }^{4}$ Bent-ol-Hoda Hospital, Mashhad University of Medical Sciences, \\ Iran \\ ${ }^{5}$ Department of Anatomy and Cell Biology, Mashhad University \\ of Medical Sciences, Iran \\ ${ }^{6}$ Medical Genetic Research Center (MGRC), Mashhad University \\ of Medical Sciences, Iran
}

\author{
Correspondence: Hossein Haghir, Department of Anatomica \\ Sciences, School of Medicine, Mashhad University of Medical \\ Sciences, Mashhad, Iran, Tel (+98)(5I)(38002486), \\ Email haghirh@mums.ac.ir
}

Received: July 26, 2016 | Published: December 16, 2016
Abbreviations: InsR, insulin receptor; CNS, central nervous system; IQ, intelligence quotient; MAPK, mitogen-activated protein kinase; PI3K, phosphoinositide 3-kinase

\section{Introduction}

Gestational Diabetes is one of the most common metabolic complications that is associated with brain development abnormalities in offspring. ${ }^{1-5}$ Several lines of studies have reported the wide spectrum of effects of gestational diabetes on the central nervous system (CNS) development and function including neurocognitive and neurodevelopmental defects. ${ }^{1-4,6-9}$ Overall, it appears that these offspring have an increased risk for lower general IQ, inattention and hyperactivity and a poorer cognitive function. ${ }^{1-4,10-13}$ Earlier investigations demonstrated a significant correlation between diabetes during pregnancy and lower IQ in offspring. ${ }^{10-13}$ There are also reports demonstrating a close relationship between maternal diabetes and a higher incidence of psychological disorders such as schizophrenia in offspring. ${ }^{14,15}$ Taken together, these studies not only suggest the teratogenic effect of gestational diabetes on the development of fetal CNS but also provide the perhaps earliest indicator of postnatal CNS problems reflected in intellectual and behavioral problems exhibited by children born to diabetic mothers. However, no report can fully explore the molecular mechanisms of gestational diabetes-induced neurocognitive defects because the CNS development is a complex process and is regulated by a number of signaling molecules and transcription factors.

Over the past few years, it has become clear that insulin has profound effects in the development and function of CNS, where it regulates several neuronal functions, including regulation of synaptic plasticity, dendritic outgrowth, and involvement in neuronal survival, life span, inhibition of neuronal apoptosis, learning and memory, and neurological disorders ${ }^{16-20}$ Moreover, the role of InsR signaling in controlling structure and function of CNS has not yet been widely explored in vivo. The InsR is also a component of synapses, where it concentrates at the postsynaptic density in cultured hippocampal neurons. ${ }^{21}$ These data together suggest that the insulin receptor is in the right place at the right time to regulate the initial neuronal development by regulating synaptic function in the CNS.

The Insulin receptor (InsR) is expressed in various areas of the developing and adult brain, ${ }^{20,22-25}$ and its functions have become the focus of recent research. The expression of the InsR in the brain was discovered decades ago. This receptor is developmentally regulated, being higher at early stages and lower in the adult and is distributed in a widespread, but selective, pattern in the brain, including cerebral cortex, hippocampus, olfactory bulb, and cerebellum as reported in rodents. ${ }^{20,22,23}$

The hippocampus-a brain structure vital for spatial learning and memory-is particularly vulnerable to changes in glucose concentration, particularly during the development. ${ }^{23,26,27}$ Considering the developmental and functional roles of insulin in the CNS, recent investigations hypothesized that the insulin may be one of the possible mechanism involved in the cognitive abnormalities observed in offspring of diabetic mothers..$^{28,29}$

\section{Discussion}

The expression of the InsR in the brain was discovered decades ago. For the first time, Havrankova et al. ${ }^{23}$ localized the InsR in the CNS. The origin of insulin in the brain has been explained from 
peripheral or central sources, or both..$^{25}$ It was found that the Insulin enters the central nervous system (CNS) by crossing the bloodbrain barrier through a receptor-mediated transport mechanism. ${ }^{30-32}$ However, the molecular identity of this transport mechanism remains unclear. Margolis et al. ${ }^{31}$ demonstrated that peripheral infusion of insulin leads to an increase in insulin levels in cerebrospinal fluid, suggesting that insulin can indeed cross the blood-brain barrier. These findings were later confirmed in studies indicating that less than $1 \%$ of the peripherally administered insulin reaches the CNS in rodents. ${ }^{32}$

The InsR belongs to the family of tyrosine kinase receptors. Binding by insulin leads to rapid auto phosphorylation of the receptor, followed by activation of downstream pathways such as the PI3K and the MAPK. ${ }^{16,18,20,23,25}$

Accumulating data support the idea that InsR signaling plays a prominent role in both developmental and functional aspects of CNS. ${ }^{16-18,20}$ In addition, emergent evidence suggests an association of InsR signaling with several neurological and neurodegenerative disorders, for example Schizophrenia, Parkinson's disease and Alzheimer's disease. ${ }^{33-36}$ InsR signaling, therefore, might participate at both ends of the story: early development as well as later neurodegenerative and psychologic disorders. Interestingly, a study By Hami et al. ${ }^{37}$ showed that there are prominent gender-and laterality- differences in expression and distribution pattern of InsR in the developing rat hippocampus. The authors concluded that these differences may be a probable mechanism for the control of sex and laterality differences in development and function of the rat hippocampus. ${ }^{37}$

Gestational diabetes is one of the most common metabolic disorders in pregnancy period and is associated with a higher risk of short- and long-term neurocognitive abnormalities in the offspring. ${ }^{1,2,4,5,7-9,28,29,38,39}$ Diabetes during pregnancy period as a result of metabolic abnormalities and perinatal complications may be associated with developing brain abnormalities in offspring, including long-lasting neurological impairment, impairments in attention and memory, hyperactivity, poorer general cognitive function and altered social behaviors. ${ }^{1,2,6,39-45}$ As yet, no distinct molecular mechanism has been identified to explain the reasons for the wide range of CNS abnormalities observed in the infants born to diabetic mothers.

To elucidate the negative impacts of gestational diabetes on cognitive functioning in the children, several researchers have been reported that diabetic mothers had offspring with significantly lower mean IQs than control infants. ${ }^{1-4,10-13}$ Moreover, many of the developmental effects of gestational diabetes on the fetal CNS can be attributed to maternal hyperglycemia and fetal hyperglycemia/ hyperinsulinemia. ${ }^{5,38,39}$ In diabetic pregnancies, the fetal blood glucose concentration is fairly high as the glucose in the mother's blood crosses the placenta freely. Therefore, In Utero hyperglycemia stimulates the pancreas of the fetuses, leads to beta-cell hyperplasia and hypertrophy with increased insulin secretion and results in fetal hyperinsulinemia. ${ }^{46,47}$

The hippocampal formation sub serves important physiological and behavioral functions including spatial learning and memory and is a part of brain that particularly vulnerable to changes in blood glucose level. ${ }^{4,8,26,27}$ Tehranipour et al. ${ }^{48}$ were examined the effects of maternal diabetes on density of hippocampal pyramidal cells immediately after birth and indicated that diabetes in pregnancy period can decreased the numerical density of pyramidal cells in the hippocampus of rat newborns. ${ }^{48}$ Recent studies have also clearly established that gestational diabetes in pregnancy disrupts the regulation of InsR in the hippocampus and cerebellum of neonatal rats. Hami et al. ${ }^{29}$ evaluated the effects of diabetes in pregnancy on gene expression and protein concentration of InsR in the developing rat hippocampus at postnatal days 0,7 , and 14 . In that study, the researchers found a markedly upregulation of InsR expression in the hippocampus of newborns born to diabetic dams at first postnatal day. At the same time point, they showed only slight changes in their hippocampal protein transcripts. In two weeks old of age rats, the InsR gene expression was strikingly declined in the hippocampus of diabetic newborns. The authors claimed that maternal diabetes strongly altered the regulation of InsR during development of rat hippocampus..$^{29}$

\section{Conclusion}

The Incidence of neurocognitive anomalies in offspring born to diabetic mothers is more common in comparison to children of normal population. Nevertheless, the exact mechanism by which gestational diabetes affects the developing CNS remains to be defined. There are multiple lines of evidence that suggest the disturbances in intellectual functioning observed in the children of diabetic women are accompanied by modification of hippocampus structure and function. The etiology and pathogenesis of these impairments induced by gestational diabetes have spurred considerable efforts for clinically and basically researches. The final goal at these studies was to find the teratogenic factors, which may enable preventive or protective measures to be taken in pregnancies with diabetes. The new researches on genetic predisposition involves in teratogenicity of diabetes in pregnancy starts to define new genes and their products involved in the etiology of CNS malfunctions and malformations observed in children born to diabetic mothers. Recent evidence clearly indicated that maternal diabetes markedly influences the regulation of InsR-as an important regulator of development and function of CNS-in the developing rat hippocampus. Dissecting out the mechanisms responsible for gestational diabetes-related changes in the development of CNS is helping to prevent from impaired cognitive and memory functions in offspring.

\section{Acknowledgements}

The authors gratefully thanks to the colleagues in department of Anatomical Sciences, Birjand University of Medical Sciences, Birjand, Iran.

\section{Conflict of interest}

Author declares that there is no conflict of interest.

\section{References}

1. Ornoy A. Growth and neurodevelopmental outcome of children born to mothers with pregestational and gestational diabetes. Pediatr Endocrinol Rev. 2005;3(2):104-113.

2. Georgieff MK. The effect of maternal diabetes during pregnancy on the neurodevelopment of offspring. Minn Med. 2006;89(3):44-47.

3. Dheen ST, Tay SS, Boran J, et al. Recent studies on neural tube defects in embryos of diabetic pregnancy: an overview. Curr Med Chem. 2009;16(18):2345-2354.

4. Hami J, Shojae F, Vafaee-Nezhad S, et al. Some of the experimental and clinical aspects of the effects of the maternal diabetes on developing hippocampus. World J Diabetes. 2015;6(3):412-422.

5. Ray JG, O'Brien TE, Chan WS. Preconception care and the risk of congenital anomalies in the offspring of women with diabetes mellitus: a meta-analysis. QJM. 2001;94(8):435-444.

6. Nelson CA, Wewerka S, Thomas KM, et al. Neurocognitive sequelae of infants of diabetic mothers. Behav Neurosci. 2000;114(5):950-956. 
7. Hami J, Karimi R, Haghir H, et al. Diabetes in pregnancy adversely affects the expression of glycogen synthase kinase-3beta in the hippocampus of rat neonates. J Mol Neurosci. 2015;57(2):273-281.

8. Lotfi N, Hami J, Hosseini M, et al. Diabetes during pregnancy enhanced neuronal death in the hippocampus of rat offspring. Int J Dev Neurosci. 2016;51:28-35.

9. Vafaei Nezhad S, Hami J, Sadeghi A, et al. The impacts of diabetes in pregnancy on hippocampal synaptogenesis in rat neonates. Neuroscience. 2016;318:122-133.

10. Yamashita Y, Kawano Y, Kuriya N, et al. Intellectual development of offspring of diabetic mothers. Acta Paediatr. 1996;85(10):1192-1196.

11. Churchill JA, Berendes HW, Nemore J. Neuropsychological deficits in children of diabetic mothers. A report from the Collaborative Sdy of Cerebral Palsy. Am J Obstet Gynecol. 1969;105(2):257-268.

12. Stehbens JA, Baker GL, Kitchell M. Outcome at ages 1, 3, and 5years of children born to diabetic women. Am J Obstet Gynecol. 1977;127(4):408-413.

13. Rizzo T, Metzger BE, Burns WJ, et al. Correlations between antepartum maternal metabolism and child intelligence. $N$ Engl J Med. 1991;325(13):911-916

14. Ramanathan M, Jaiswal AK, Bhattacharya SK. Hyperglycaemia in pregnancy: effects on the offspring behaviour with special reference to anxiety paradigms. Indian J Exp Biol. 2000;38(3):231-236.

15. Van Lieshout RJ, Voruganti LP. Diabetes mellitus during pregnancy and increased risk of schizophrenia in offspring: a review of the evidence and putative mechanisms. J Psychiatry Neurosci. 2008;33(5):395-404.

16. Plum L, Schubert M, Bruning JC. The role of insulin receptor signaling in the brain. Trends Endocrinol Metab. 2005;16(2):59-65.

17. Reagan LP. Insulin signaling effects on memory and mood. Curr Opin Pharmacol. 2007;7(6):633-637.

18. Chiu SL, Cline HT. Insulin receptor signaling in the development of neuronal structure and function. Neural Dev. 2010;5:7.

19. Agrawal R, Tyagi E, Shukla R, et al. Insulin receptor signaling in rat hippocampus: a study in STZ (ICV) induced memory deficit model. Eur Neuropsychopharmacol. 2011;21(3):261-273.

20. Wozniak M, Rydzewski B, Baker SP, et al. The cellular and physiological actions of insulin in the central nervous system. Neurochem Int. 1993;22(1):1-10.

21. Abbott MA, Wells DG, Fallon JR. The insulin receptor tyrosine kinase substrate p58/53 and the insulin receptor are components of CNS synapses. J Neurosci. 1999;19(17):7300-7308.

22. Unger J, McNeill TH, Moxley RT 3rd, et al. Distribution of insulin receptor-like immunoreactivity in the rat forebrain. Neuroscience. 1989;31(1):143-157.

23. Havrankova J, Roth J, Brownstein M. Insulin receptors are widely distributed in the central nervous system of the rat. Nature. 1978;272(5656):827-829.

24. Kar S, Chabot JG, Quirion R. Quantitative autoradiographic localization of [125I] insulin-like growth factor I, [125I] insulin-like growth factor II, and [125I] insulin receptor binding sites in developing and adult rat brain. J Comp Neurol. 1993;333(3):375-397.

25. Marks JL, Porte D Jr, Stahl WL, et al. Localization of insulin receptor mRNA in rat brain by in situ hybridization. Endocrinology. 1990;127(6):3234-3236.

26. Forster E, Zhao S, Frotscher M. Laminating the hippocampus. Nat Rev Neurosci. 2006;7(4):259-267.
27. Thompson CL, Pathak SD, Jeromin A, et al. Genomic anatomy of the hippocampus. Neuron. 2008;60(6):1010-1021.

28. Haghir H, Rezaee AA, Sankian M, et al. The effects of induced type-I diabetes on developmental regulation of insulin \& insulin like growth factor-1 (IGF-1) receptors in the cerebellum of rat neonates. Metab Brain Dis. 2013;28(3):397-410.

29. Hami J, Sadr Nabavi A, Sankian M, et al. The effects of maternal diabetes on expression of insulin-like growth factor-1 and insulin receptors in male developing rat hippocampus. Brain Struct Funct. 2013;218(1):73-84.

30. Banks WA, Jaspan JB, Huang W, et al. Transport of insulin across the blood-brain barrier: saturability at euglycemic doses of insulin. Peptides. 1997;18(9):1423-1429.

31. Margolis RU, Altszuler N. Insulin in the cerebrospinal fluid. Nature. 1967;215(5108):1375-1376.

32. Woods SC, Porte DJ. Relationship between plasma and cerebrospinal fluid insulin levels of dogs. Am J Physiol. 1977;233(4):E331-E334

33. Blazquez E, Velazquez E, Hurtado Carneiro V, et al. Insulin in the brain: its pathophysiological implications for States related with central insulin resistance, type 2 diabetes and Alzheimer's disease. Front Endocrinol (Lausanne). 2014;5:161.

34. Steen E, Terry BM, Rivera EJ, et al. Impaired insulin and insulin-like growth factor expression and signaling mechanisms in Alzheimer's disease--is this type 3 diabetes? J Alzheimers Dis. 2005;7(1):63-80

35. Zhao WQ, De Felice FG, Fernandez S, et al. Amyloid beta oligomers induce impairment of neuronal insulin receptors. FASEB J. 2008;22(1):246-260.

36. Moroo I, Yamada T, Makino $\mathrm{H}$, et al. Loss of insulin receptor immunoreactivity from the substantia nigra pars compacta neurons in Parkinson's disease. Acta Neuropathol. 1994;87(4):343-348.

37. Hami J, Sadr Nabavi A, Sankian M, et al. Sex differences and leftright asymmetries in expression of insulin and insulin-like growth factor-1 receptors in developing rat hippocampus. Brain Struct Funct. 2012;217(2):293-302.

38. Meur S, Mann NP. Infant outcomes following diabetic pregnancies. Paediatrics and Child Health. 2007;17(6):217-222.

39. Schwartz R, Teramo KA. Effects of diabetic pregnancy on the fetus and newborn. Semin Perinatol. 2000;24(2):120-135.

40. Ryan EA, Liu D, Bell RC, et al. Long-term consequences in offspring of diabetes in pregnancy: studies with syngeneic islet-transplanted streptozotocin-diabetic rats. Endocrinology. 1995;136(12):5587-5592.

41. Sells CJ, Robinson NM, Brown Z, et al. Long-term developmental follow-up of infants of diabetic mothers. J Pediatr. 1994;125(1):S9 S17.

42. Silverman BL, Rizzo T, Green OC, et al. Long-term prospective evaluation of offspring of diabetic mothers. Diabetes. 1991;40(Suppl 2):121-125.

43. Stenninger E, Flink R, Eriksson B, et al. Long-term neurological dysfunction and neonatal hypoglycaemia after diabetic pregnancy. Arch Dis Child Fetal Neonatal Ed. 1998;79(3):F174-F179.

44. ter Braak EW, Evers IM, Willem Erkelens D, et al. Maternal hypoglycemia during pregnancy in type 1 diabetes: maternal and fetal consequences. Diabetes Metab Res Rev. 2002;18(2):96-105.

45. Van Assche FA, Holemans K, Aerts L. Long-term consequences for offspring of diabetes during pregnancy. Br Med Bull. 2001;60:173-182.

46. Pedersen J. Weight and length at birth of infants of diabetic mothers. Acta Endocrinol (Copenh). 1954;16(4):330-342. 
47. Pedersen J. The pregnant diabetic and her newborn. Baltimore: Williams \& Wilkins; 1977.
48. Tehranipour M, Khakzad MR. Effect of maternal diabetes on hippocampus neuronal density in neonatal rats. $J$ Biol Sci. 2008;8(6):1027-1032. 